\title{
COMPORTAMENTO DAS FERMENTAÇÕES ALCOÓLICA E ACÉTICA DE SUCOS DE KIWI (Actinidia deliciosa); COMPOSIÇÃO DOS MOSTOS E MÉTODOS DE FERMENTAÇÃO ACÉTICA ${ }^{1}$
}

\author{
Fabiana BORTOLINI ${ }^{2}$, Ernani Sebastião SANT'ANNA ${ }^{2, *}$, Regina Coeli TORRES ${ }^{2}$
}

\begin{abstract}
RESUMO
A cultura de kiwi vem se expandindo e a obtenção de vinagre é uma alternativa para o aproveitamento de excedentes de safra e diversificação da produção. Os mostos foram preparados em seis tratamentos: suco de kiwi natural (T1); suco de kiwi e nutrientes (T2); suco de kiwi e sacarose até $18^{\circ} \mathrm{Brix}$ (T3); suco de kiwi a $18^{\circ}$ Brix, e nutrientes (T4); suco de kiwi e sacarose até $22^{\circ}$ Brix (T5) e suco de kiwi a $22^{\circ}$ Brix, e nutrientes (T6). A fermentação alcoólica ocorreu a $28^{\circ} \mathrm{C}$, com inóculo de $10^{\circ} \mathrm{UFC} / \mathrm{mL}$ de Saccharomyces cerevisiae. Foram utilizados na fermentação acética apenas os tratamentos 1, 3 e 5, considerando que a adição de nutrientes não influenciou a produção de etanol. $\mathrm{Na}$ fermentação acética, foram utilizados gerador vertical (PG) a temperatura ambiente e fermentador submerso (PS) a $25^{\circ} \mathrm{C}$, com agitação de $500 \mathrm{rpm}$ e fluxo de oxigênio de $0,05 \mathrm{vvm}$, com volume de trabalho de 2 litros. Os rendimentos da fermentação alcoólica variaram entre 38,65 e 47,23\%, com eficiências de 75,62 a $92,41 \%$ e produtividades entre 0,74 e $2,0 \mathrm{~g} / \mathrm{L}$.h. Os valores de $\mathrm{pH}$ foram maiores ao final da fermentação alcoólica nos mostos com menor concentração de açúcares totais (T1 e T2). Na fermentação acética pelo PG, a composição dos mostos não aumentou a produtividade, por outro lado, pelo PS, os mostos com concentrações de etanol superiores foram mais produtivos. Os vinagres obtidos pelo PS produziram em 12 horas entre 1,00 e $1,78 \%(\mathrm{p} / \mathrm{v})$ de ácido acético, com rendimentos variando entre 93,24 e $98,34 \%$ e produtividades entre 0,83 e 1,73g/L.h. A análise sensorial, através do teste de ordenação, indicou que os vinagres de kiwi obtidos pelo PG foram superiores, com índices de aceitabilidade acima de $70 \%$.
\end{abstract}

Palavras-chave: Actinidia deliciosa; kiwi; vinagre; fermentação acética.

\section{SUMMARY}

BEHAVIOUR OF ALCOHOLIC AND ACETIC FERMENTATIONS OF KIWI MASHES (Actinidia deliciosa); COMPOSITION OF MASHES AND PRODUCTION METHODS. The kiwi culture has been expanding and the production of vinegar is an alternative that aims to use surplus fruits to diversify production. In this study, kiwi fruit (Actinidia deliciosa) vinegar was produced using submerse and generator methods. Mashes were prepared in six treatments: natural kiwi fruit juice (T1); kiwi fruit juice and nutrients added (T2); kiwi fruit juice and sucrose until $18^{\circ} \mathrm{Brix}$ (T3); kiwi fruit juice and sucrose until $18^{\circ}$ Brix and nutrients (T4); kiwi fruit juice and sucrose until $22^{\circ} \mathrm{Brix}$ (T5); and kiwi fruit juice and sucrose until $22^{\circ}$ Brix and nutrients (T6). The alcoholic fermentation occurred at $28^{\circ} \mathrm{C}$, with $10^{6} \mathrm{CFU} / \mathrm{mL}$ of Saccharomyces cerevisiae. Only treatments 1,3 and 5 were used in the acetic fermentation since the addition of nutrients didn't influence ethanol production. In acetic fermentation vertical generator (PG), at room temperature, and submerged fermentator (PS), at $25^{\circ} \mathrm{C}, 500 \mathrm{rpm}$ agitation an

${ }^{1}$ Recebido para publicação em 20/04/01. Aceito para publicação em 31/07/01.

${ }^{2}$ Departamento de Ciência e Tecnologia de Alimentos da Universidade Federal de Santa Catarina, Centro de Ciências Agrárias. Rodovia Admar Gonzaga n. 1346. Bairro Itacorubi. CEP 88034001, Florianópolis, SC.

${ }^{*}$ A quem a correspondência deve ser enviada. oxygen flow of $0.05 \mathrm{vvm}$, both in a 2 -liter work volume were utilised. The alcoholic fermentation yield varied between 38.65 and $47.23 \%$, with efficiency of 75.62 to $92.41 \%$ and it's productivity between 0.74 and $2.0 \mathrm{~g} / \mathrm{L}$.h. The $\mathrm{pH}$ values were higher at the end of the process in treatments with lower concentrations of total sugars (T1 and T2). In acetic fermentation at the PG, the composition of mashes didn't increase acetic acid production, but for PS initial higher concentrations of ethanol were more productive. The vinegars obtained by PS, produced in 12 hours between 1.00 and $1.78 \%$ $(\mathrm{p} / \mathrm{v})$ acetic acid, with yields varying between 93.24 and $98.34 \%$ and productivity between 0.83 and $1.73 \mathrm{~g} / \mathrm{L}$.h. The sensory analysis performed with a ranking test showed that kiwi fruit vinegars obtained by PG were better than those obtained by PS, with acceptability indexes above $70 \%$. The analyzed data showed that it is possible to produce kiwi fruit vinegar using surplus production fruits to diversify the products.

Keywords: Actinia deliciosa; vinegar; fermentation; mashes composition; production methods.

\section{1 - INTRODUÇÃO}

$O$ vinagre é utilizado no mundo inteiro como condimento e conservante de alimentos [11]. Além disso é considerado um complemento indispensável à alimentação humana, pela ação nutritiva e biorregulatória [17]. É produzido por dois processos bioquímicos distintos, ambos resultantes da ação de microrganismos: a fermentação alcoólica, pela ação de leveduras sobre matérias-primas açucaradas e amiláceas e a fermentação acética, pela ação de bactérias aeróbias do gênero Acetobacter [15, 26, 28].

A fabricação de vinagre proporciona um meio de utilização de matéria-prima inaproveitável dos estabelecimentos industriais de frutas e especialmente de propriedades rurais, que de outra forma, não poderiam competir no mercado [10]. Vinagres de frutas são considerados superiores em qualidades sensoriais e nutritivas, quando comparados a outros tipos de vinagres, apresentando características como sabor e aroma próprios [15]. Sob o aspecto nutricional, têm vitaminas, ácidos orgânicos, proteínas e aminoácidos provenientes do fruto e da fermentação alcoólica [2].

O Brasil é um importante produtor mundial de frutas, e no entanto o país apresenta altos índices de perdas pós-colheita, incluindo o não aproveitamento de excedentes de safra [8]. O Estado de Santa Catarina destaca-se como o principal produtor nacional de kiwi, com uma produção aproximada no ano 2000, de $2500 t$ [9]. Sua utilização industrial tem importância cada vez maior, pela disponibilidade das frutas de maneira diversa durante todo o ano, e pelo aproveitamento daquelas que apresentam defeitos (calcula-se de $10-15 \%$ da produção anual), sem qualidade para consumo in natura [21]. 
Este trabalho foi realizado com o objetivo de avaliar as fermentações alcoólica e acética de sucos de kiwi em diferentes composições de mosto, utilizando dois processos rápidos de acetificação: gerador e submerso, oferecendo com isso, alternativa para o produtor, na diversificação de produtos derivados de kiwi e para a diminuição de perdas pós-colheita.

\section{2 - MATERIAL E MÉTODOS}

\section{1 - Matéria-prima}

A matéria-prima utilizada foi uma mistura de cultivares de kiwis (Actinidia deliciosa) excedentes de safra, com grau de maturação uniforme, adquiridas em feiras comerciais.

\section{2 - Microrganismos}

Para a fermentação alcoólica, foi utilizado um cultivo puro de Saccharomyces cerevisiae, a partir de fermento comercial desidratado. A fermentação acética foi conduzida pela inoculação de bactérias ácido-acéticas provenientes de vinagre de mel não pasteurizado (vinagre forte), fornecido por uma indústria.

\section{3 - Fermentação alcoólica}

\subsection{1 - Preparo do mosto}

O homogeneizado foi submetido a seis tratamentos em cinco repetições: T1- suco da fruta natural (controle); T2- suco da fruta natural com adição de sais inorgânicos (sulfato de amônia $0,2 \mathrm{~g} / \mathrm{L}$, fosfato de amônia $1,0 \mathrm{~g} / \mathrm{L}$ e sulfato de magnésio $0,1 \mathrm{~g} / \mathrm{L}$ ); T3- suco da fruta com correção do grau Brix para $18 \%$ de sólidos solúveis totais (SST) pela adição de sacarose (comercial); T4- suco da fruta com $18 \%$ de SST, adicionado de sacarose e sais inorgânicos; T5- suco da fruta com correção do grau Brix para 22\% de SST; T6- suco da fruta com $22 \%$ de SST, adicionado de sacarose e sais inorgânicos. A fermentação alcoólica foi conduzida em cubas de polietileno com capacidade de 2,5L, em estufa. $O$ volume de trabalho foi de $1000 \mathrm{~mL}$, a temperatura de $28^{\circ} \mathrm{C}( \pm 1)$. Em cada tratamento foi adicionado inóculo na proporção de $10 \%$ com uma população de $10^{6} \mathrm{UFC} / \mathrm{mL}$. Os vinhos obtidos foram centrifugados a 3000rpm por 20 minutos, pasteurizados $\left(65^{\circ} \mathrm{C} / 20\right.$ minutos $)$ e congelados $\left(-18^{\circ} \mathrm{C}\right)$ para a posterior fermentação acética.

\subsection{2 - Acompanhamento da fermentação}

Durante a fermentação alcoólica foram determinadas as concentrações de: açúcares totais, pelo método Clegg Anthrone [20] ; concentração de etanol, pelo método da oxidação do dicromato (técnica $n^{\circ}$ 962.12) [3] e $\mathrm{pH}$ [13].

A população de leveduras viáveis foi determinada utilizando-se a técnica de semeadura em profundidade com incubação a $25^{\circ} \mathrm{C} / 5$ dias [18].

\subsection{3 - Cálculo do rendimento e eficiência da fermentação alcoólica}

- Rendimento da fermentação, foi calculado utilizandose os valores de etanol produzido ( $\% \mathrm{p} / \mathrm{v})$ em relação aos açúcares consumidos (\% p/v) x 100 [2].

- Eficiência da fermentação, pela relação: álcool produzido $(\% \mathrm{p} / \mathrm{v}) /$ álcool teórico $(\% \mathrm{p} / \mathrm{v}) \times 100$. O álcool teórico é calculado a partir dos açúcares consumidos $x$ 0,5111.

- Produtividade da fermentação: foi calculada considerando-se o etanol produzido (p/v) em relação ao tempo total de fermentação (horas), em (g/L.h) [2].

\section{4 - Fermentação acética}

\subsection{1 - Preparo do mosto e acompanhamento da fermentação}

Para a produção de vinagre foram utilizados os vinhos obtidos na fermentação alcoólica, dos tratamentos 1,3 e 5 com teores alcoólicos de 3,54\%, 6,74\% e $9,43 \%(p / v)$, respectivamente, submetidos à fermentação acética: TA: vinho com 3,54\% de etanol (p/v); TB: vinho com $6,74 \%$ de etanol ( $p / v)$; TC: vinho com $9,43 \%$ de etanol $(p / v)$, em processo por gerador; TD: vinho com $3,54 \%$ de etanol (p/v); TE: vinho com $6,74 \%$ de etanol (p/v); TF: vinho com 9,43\%, de etanol ( $p / v)$, em processo submerso.

\subsection{2 - Processo do gerador}

Foi realizado em gerador vertical, construído em PVC, dividido em: depósito inferior, para a adição de mosto e para retirada de vinagre, compartimento intermediário (onde ocorre a fixação das bactérias sobre o material de suporte contendo pedaços de carvão vegetal esterilizados) e depósito superior (ou reservatório, de onde o mosto circulou sobre o compartimento intermediário). A fermentação foi conduzida em temperatura ambiente $\left(20\right.$ a $25^{\circ} \mathrm{C}$ ) nas 5 (cinco) repetições, com volume de trabalho de 2 litros. Os vinhos foram enriquecidos com sulfato de amônio $0,1 \mathrm{~g} / \mathrm{L}$, fosfato de amônio $0,5 \mathrm{~g} / \mathrm{L}$, fosfato de potássio $0,1 \mathrm{~g} / \mathrm{L}$, sulfato de magnésio $0,1 \mathrm{~g} / \mathrm{L}$ e glicose $1,0 \mathrm{~g} / \mathrm{L}$.

Durante o processo de acetificação, a adição de vinho de kiwi foi feita retirando-se $500 \mathrm{~mL}$ de vinagre com teor alcoólico inferior a 1,0\% (v/v) e adicionandose igual quantidade de vinho a cada 24 horas do processo fermentativo. Foram realizadas coletas para análises de acidez e teor alcoólico. Cada adição de novo mosto alcoólico foi considerada uma repetição do experimento. A circulação do mosto no interior do gerador ocorreu em intervalos de 15 minutos.

\subsection{3 - Processo submerso}

Os mostos foram acetificados em fermentador (New Brunswick Cientific, Modelo Bioflo 2000), no qual foram controlados o fluxo de oxigênio $(0,05 \mathrm{vvm}$ - volume de ar/volume de mosto $x$ minuto), a temperatura $\left(25^{\circ} \mathrm{C}\right)$ 
e a velocidade de agitação (500rpm). Durante a fermentação acética, foram realizadas coletas em intervalos de 6 (seis) horas, em triplicata, para análise de acidez e teor alcoólico. O volume de trabalho foi de 2 litros. A adição do clarificante Acetozim (R) foi realizada numa proporção de $0,1 \mathrm{~g} / \mathrm{L}$, facilitando a filtração.

O vinagre foi retirado com teor alcoólico abaixo de $1,0 \%$ de etanol (v/v). Após a retirada de $500 \mathrm{~mL}$ do produto foi feita a substituição por novo vinho, utilizandose como inóculo parte da batelada anterior que permaneceu no fermentador. A adição dos mostos alcoólicos dos diferentes tratamentos ocorreu a cada 12 horas do processo fermentativo.

\subsection{4 - Acompanhamento da fermentação}

Nos produtos finais foram realizadas, em triplicata, as seguintes determinações: concentração de etanol pelo método da oxidação do dicromato (técnica $n^{\circ}$ 962.12) [3]; acidez fixa em ácido acético (técnica $n^{\circ}$ 930.35) [3]; resíduo mineral fixo (técnica $n^{\circ} 900.02$ ) [3]; resíduo seco a $105^{\circ} \mathrm{C}$ (técnica $\mathrm{n}^{\circ} 920.68$ ) [3]. A acidez foi expressa em $\%$ de ácido acético $(p / v)$ e o teor alcoólico, em $\%$ de etanol $(p / v)$.

\subsection{5 - Cálculo do rendimento e produtividade da fermentação acética}

O rendimento foi calculado de duas maneiras: (a)Produção observada de ácido acético em relação ao rendimento teórico. O rendimento teórico é calculado a partir da reação de conversão do etanol a ácido acético, onde $1,0 \mathrm{~g}$ de etanol rende $1,304 \mathrm{~g}$ de ácido acético [2]. (b)- Concentração total ou GK (Gesammte Konzentration), calculada pela eficiência da fermentação expressa pela soma da concentração de etanol (\% v/v) e ácido acético $(\% \mathrm{p} / \mathrm{v})$ no início e final da fermentação [7]. Essa relação foi aplicada para calcular a eficiência com a qual o etanol é convertido a ácido acético: Rendimento GK = (GK final/GK inicial) x 100. A produtividade foi calculada pela quantidade produzida de ácido acético em relação ao volume e tempo (g/L.h).

\subsection{6 - Tratamento final do vinagre}

Os vinagres obtidos foram diluídos em água destilada para uma acidez de $5,0 \%$. Para os vinagres resultantes do processo submerso, foi adicionada bentonita $(0,05 \% \mathrm{p} / \mathrm{v})$, por um período de 8 horas para sedimentação. Posteriormente os vinagres foram centrifugados, filtrados, engarrafados e pasteurizados a $65^{\circ} \mathrm{C} / 20 \mathrm{mi}-$ nutos. Pesquisa de sujidades foi realizada segundo a técnica $n^{\circ} 970.66$ [3]. O material retido no papel filtro foi examinado em microscópico estereoscópico.

\subsection{7 - Análise sensorial}

As avaliações sensoriais dos vinagres foram realizadas pela equipe de julgadores do Departamento de Ciência e Tecnologia de Alimentos da Universidade Federal de Santa Catarina. Para a avaliação dos atributos aspecto, cor e odor, as amostras foram distribuídas em tubos de ensaio com tampa rosqueável, cada um contendo $10 \mathrm{~mL}$, enquanto que, para a avaliação do sabor, foram provadas puras e oferecidas com folhas de alface cortadas. Foi feito uso de escala de valores, cuja pontuação variou de 01 (um) a 03 (três), sendo 01 (um) péssimo, 02 (dois) bom, e 03 (três) ótimo [29]. As amostras foram codificadas ao acaso, com o auxílio de uma tabela de números aleatórios. Os vinagres considerados aceitos em termos de suas propriedades sensoriais foram aqueles que alcançaram o índice de aceitabilidade mínimo de $70 \%$, considerando-se $100 \%$ a pontuação máxima alcançada pelo produto, utilizando-se a mesma escala de valores [19].

\subsection{8 - Análise estatística}

Para as análises dos componentes etanol e população de leveduras foram utilizados modelos não-lineares de GOMPERTZ com 3 (três) parâmetros, sendo ajustado um modelo para cada tratamento. A análise estatística de $\mathrm{pH}$ foi realizada através de ajustes de modelos de regressão linear. O modelo linear foi utilizado para verificar diferenças estatísticas entre as equações ajustadas. Para a fermentação acética, foram realizados ajustes de modelos de regressão linear simples. Para os componentes etanol e ácido acético, foram ajustadas 6 (seis) retas. Foram feitos testes de hipótese para comparar estes tratamentos em relação aos efeitos de concentração dos mostos e processos de acetificação. O programa estatístico utilizado foi o SAS através do PROC MIXED, versão 6.12 [24].

A análise estatística das avaliações sensoriais foi conduzida pela aplicação do teste de ordenação, segundo o delineamento de blocos incompletos balanceados, pelo teste T de Durbin [1] (NBR 13170). As avaliações foram realizadas por 18 provadores (blocos), cada um avaliando 3 tratamentos com 9 (nove) repetições cada [25]. Foi aplicado o teste de comparações múltiplas, considerando-se o nível de erro de $5 \%$. Os cálculos foram efetuados através do programa estatístico Statgraphics [27].

\section{3 - RESULTADOS E DISCUSSÃO}

\section{1 - Caracterização da matéria-prima}

A polpa in natura apresentou uma concentração aproximada de sólidos solúveis totais (SST) de $14^{\circ} \mathrm{Brix}$, correspondendo a $9,47 \%(p / v)$ de açúcares totais.

\section{2 - Fermentação alcoólica}

\subsection{1 - Açúcares totais}

Os mostos de kiwi apresentaram concentrações de açúcares totais superiores nos tratamentos 5 e 6 (cerca de $20,0 \%$ p/v) devido à adição de sacarose, e menores nos tratamentos 1 e 2 (cerca de 9,0\% p/v). Os açúcares totais consumidos, podem ser observados na Tabela 1. As concentrações de açúcares residuais encontradas foram menores que $0,33 \%(p / v)$, indicando a eficiência das fermentações realizadas. AQUARONE \& ZANCANARO JR. [2] encontraram, ao final de fermen- 
tações, teores de açúcares residuais próximos a 0,5\% em mostos de uva.

\subsection{2 - Etanol}

Neste trabalho foram verificados os teores médios de etanol entre $3,54 \%$ e $9,61 \%(\mathrm{p} / \mathrm{v})$, respectivamente, para os tratamentos 1 a 6 (Tabela 1) produzidos num período de 48 horas.

TABELA 1. Consumo de açúcares totais, produção de etanol, rendimento e eficiência da fermentação alcoólica de mostos de kiwi em seis tratamentos.

\begin{tabular}{ccccccc}
\hline Tratamento & $\begin{array}{c}\text { Açúcares } \\
\text { consumidos } \\
\%(\mathbf{p} / \mathbf{v})^{*}\end{array}$ & $\begin{array}{c}\text { Etanol } \\
\text { produzido } \\
\%(\mathbf{p} / \mathbf{v})^{*}\end{array}$ & $\begin{array}{c}\text { Etanol } \\
\text { teórico\% } \\
(\mathbf{p} / \mathbf{v})\end{array}$ & $\begin{array}{c}\text { Rendimento } \\
\%\end{array}$ & $\begin{array}{c}\text { Eficiência } \\
\%\end{array}$ & $\begin{array}{c}\text { Produtividade } \\
\mathbf{( g / L . h})\end{array}$ \\
\hline T 1 & 9,159 & 3,540 & 4,681 & 38,650 & 75,624 & 0,738 \\
T 2 & 9,113 & 3,648 & 4,657 & 40,031 & 78,333 & 0,760 \\
T 3 & 15,498 & 6,742 & 7,921 & 43,502 & 85,137 & 1,404 \\
T 4 & 15,426 & 7,054 & 7,884 & 45,728 & 89,484 & 1,469 \\
T 5 & 20,286 & 9,483 & 10,368 & 46,746 & 91,482 & 1,975 \\
T 6 & 20,338 & 9,605 & 10,394 & 47,226 & 92,409 & 2,001 \\
\hline
\end{tabular}

${ }^{*}$ Média de cinco repetições

Aproximadamente $95 \%$ do etanol foi produzido entre 34 horas (T1 a T4) e 40 horas (T5 e T6).

Tratamentos com maiores concentrações de açúcares totais (T5 e T6) no início da fermentação, podem promover uma inibição e retardar o consumo por parte das leveduras [14]. Mesmo assim, a fermentação alcoólica desenvolveu-se normalmente e poderia ser encerrada em 40 horas (T5 e T6). Por outro lado, para menores concentrações de açúcares (T1 a T4), pode-se considerar que a fermentação poderia ser concluída em 36 horas com açúcares residuais e teor alcoólico quase constantes.

Os rendimentos encontrados variaram de $38,65 \%$ a $47,23 \%$, com eficiências que corresponderam a conversão de 75,62 a $92,41 \%$ dos açúcares totais presentes no meio, tendo sido superiores nos tratamentos 5 e 6 , os quais apresentaram as concentrações de açúcares totais mais elevadas. O mesmo pode ser verificado para a produtividade, que variou entre os tratamentos de 0,738 a $2,001 \mathrm{~g} / \mathrm{L} . \mathrm{h}$, sendo que os maiores valores foram encontrados nos tratamentos 5 e 6 (Tabela 1).

A Figura 1 apresenta os resultados médios de produção de etanol durante a fermentação alcoólica para os seis tratamentos, sendo que os pontos correspondem aos valores observados e as linhas contínuas, aos modelos ajustados.

Segundo a análise estatística, existe diferença significativa entre os tratamentos analisados. Os resultados mostram que a adição de nutrientes (tratamentos 2, 4 e 6) não foi significativa para um aumento na produção de etanol, o que pode ser atribuído ao conteúdo de nutrientes da fruta.

Por outro lado, e como era esperado, a adição de açúcares foi significativa para a produção de etanol, o que foi verificado pela variação significativa $(p=0,0001)$, sendo que, teores maiores de SST favoreceram uma maior produção de etanol.

\subsection{3 - População de leveduras}

A utilização de cultura pura de $S$. cerevisiae, numa concentração de $10,0 \%$ (v/v) de inóculo, a exemplo de BHATT et al [4], mostrou-se adequada para a obtenção de teores alcoólicos adequados, para uma posterior utilização para a fermentação acética (Figura 2). A população de leveduras aumentou aproximadamente de $10^{6} \mathrm{UFC} / \mathrm{mL}$ para $10^{11} \mathrm{UFC} / \mathrm{mL}$, sendo que o pico máximo de crescimento ocorreu entre 12 e 36 horas (Figura 2).

Nos ensaios com os tratamentos 1 e 2 (Brix natural), obteve-se um teor alcoólico final médio de 3,6\% $(p / v)$, considerado insuficiente para causar inibição ao desenvolvimento de leveduras. CIANI [6] relata que o teor de etanol de $8,2 \%(\mathrm{p} / \mathrm{v})$ foi inibitório para o crescimento celular em seus experimentos. Neste experimento, mesmo utilizando-se concentrações relativamente elevadas de açúcares, não se verificou inibição do crescimento celular pela produção de etanol e a fermentação se desenvolveu dentro dos parâmetros normais de uma fermentação alcoólica.

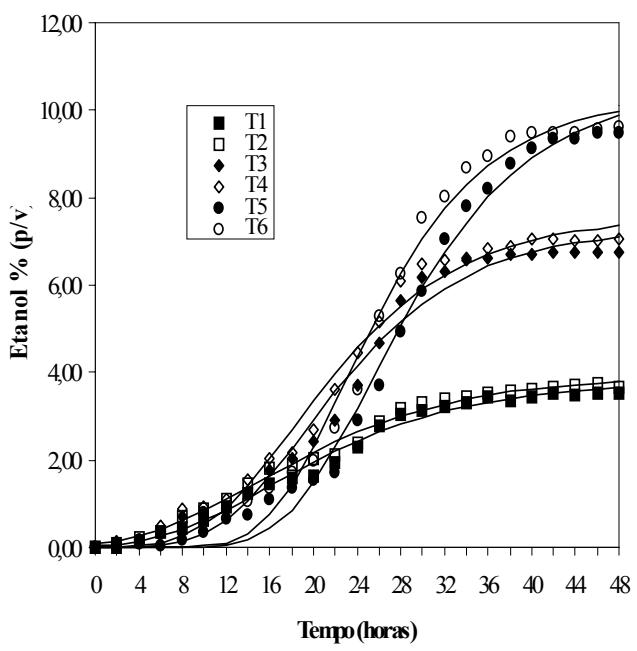

FIGURA 1. Produção de etanol e duração da fermentação alcoólica de mostos de kiwi nos seis tratamentos analisados.

Os modelos ajustados para a análise estatística da população de leveduras, podem ser observados na Figura 2, sendo que os pontos correspondem aos valores observados e as linhas contínuas aos modelos ajustados. Para todas as hipóteses testadas, não se verificou diferença significativa entre os tratamentos, para os contrastes analisados. Os valores de $p$ obtidos ficaram acima de 0,4185 . Portanto, não foi verificada inibição do crescimento celular pelas diferentes concentrações de etanol produzidas, e o aumento da população de leveduras não foi influenciado pela concentração de açúcares e pela adição de nutrientes, em nenhum tratamento.

\subsection{4 - pH}

Os valores de $\mathrm{pH}$ iniciais variaram de 3,8 a 4,0 entre os tratamentos. Esta faixa de $\mathrm{pH}$ utilizada foi suficiente para permitir uma rápida fermentação alcoólica e inibir 
bactérias indesejáveis. Ao longo do processo fermentativo, foi verificada uma pequena queda, própria da produção de ácidos orgânicos, reduzindo os valores de $\mathrm{pH}$ iniciais para uma faixa aproximada de 3,6.

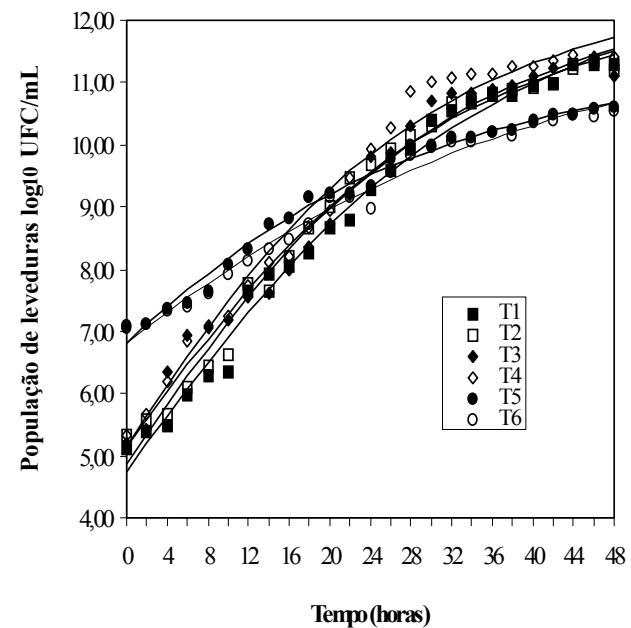

FIGURA 2. Curvas de crescimento de $S$. cerevisiae durante a fermentação alcoólica em mostos de kiwi nos diferentes tratamentos.

Pela análise estatística, foi verificado que existem diferenças significativas. Apenas os tratamentos com diferentes concentrações de açúcares variaram entre si, não sendo verificada diferença com a adição de nutrientes e, portanto, para este fator, todos os tratamentos são estatisticamente iguais. Os valores de $\mathrm{pH}$ no final do processo fermentativo foram superiores para os tratamentos 1 e 2 , seguidos dos tratamentos $3,4,5$ e 6 .

\section{3 - Fermentação acética}

A fermentação acética para o processo do gerador (TA, TB e TC) ocorreu a temperatura ambiente que variou de $20,4^{\circ} \mathrm{C}$ a $24,9^{\circ} \mathrm{C}$ durante as cinco repetições do experimento, sendo que, no interior do gerador, a temperatura variou de $21,1^{\circ} \mathrm{C}$ a $27,5^{\circ} \mathrm{C}$.

O processo submerso (TD, TE e TF) foi controlado, não havendo nenhuma alteração desses fatores ao longo do processo. Foi verificado que as bactérias acéticas utilizadas, provenientes de vinagre de mel não pasteurizado, foram eficientes na produção de ácido acético nos dois processos analisados. A Figura 3 apresenta o consumo médio de etanol em função do tempo de fermentação, nos dois processos de acetificação. Pode ser observado que o tempo para oxidação do etanol a ácido acético foi de 12 horas para o processo submerso e de 24 horas para o processo do gerador, quando era feita a retirada de vinagre e nova adição de mosto.

Adicionalmente, pode ser observado que no processo do gerador, o comportamento das curvas de oxidação do etanol foi semelhante para todas as composições (TA, TB, TC), enquanto para o processo submerso (TD, TE e TF), concentrações de etanol superiores apre- sentaram quedas mais acentuadas, atingindo em 12 horas valores de etanol abaixo de 1,0\% (p/v).

Segundo a reação estequiométrica, que representa a transformação do etanol a ácido acético, $1,0 \mathrm{~g}$ de etanol pode fornecer $1,304 \mathrm{~g}$ de ácido acético. Industrialmente, a conversão de $1,0 \mathrm{~g}$ de etanol a $1,0 \mathrm{~g}$ de ácido acético (rendimento de $76,7 \%$ ) é considerada econômica [2].

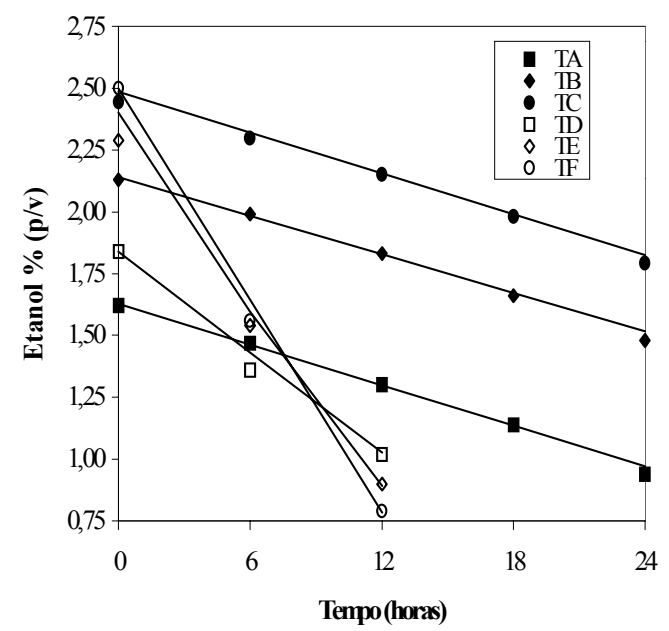

FIGURA 3. Consumo médio de etanol\% $(p / v)$ e duração da fermentação acética de vinhos de kiwi para os processos gerador e submerso em diferentes tratamentos.

A Tabela 2 apresenta o rendimento e a produtividade da fermentação acética, calculados segundo AQUARONE \& ZANCANARO JR. [2]. Os rendimentos foram acima de $80,0 \%$, atingindo valores de até $98,34 \%$ (TE), e produtividades entre 0,29 e 1,73g/L.h. Com isso, pode-se dizer que foram baixas as perdas por evaporação de compostos voláteis nos processos submerso e gerador, o que pode ser atribuído a aeração e temperatura adequadas aos meios. De acordo com EBNER [7], na ausência de perdas por evaporação ou superoxidação, a concentração total ou GK (concentração de etanol (v/v) + concentração de ácido acético ( $p / v)$ ), permanece constante durante o período de acetificação. Esta relação pode ser aplicada para calcular a eficiência com a qual o etanol é convertido a ácido acético (Tabela 3).

TABELA 2. Consumo de etanol, produção de ácido acético, rendimento e produtividade da fermentação acética de vinhos de kiwi em processos gerador e submerso.

\begin{tabular}{cccccc}
\hline Tratamento & $\begin{array}{c}\text { Etanol } \\
\text { consumido } \\
\%(\mathbf{p} / \mathbf{v})\end{array}$ & $\begin{array}{c}\text { Acido } \\
\text { acético }^{(*)} \\
\text { produzido } \\
\%(\mathbf{p} / \mathbf{v})\end{array}$ & $\begin{array}{c}\text { Ácido } \\
\text { acético } \\
\text { teórico } \% \\
(\mathbf{p} / \mathbf{v})\end{array}$ & $\begin{array}{c}\text { Rendimento } \\
\%\end{array}$ & $\begin{array}{c}\text { Produtividade } \\
(\mathbf{g} / \mathbf{L} . \mathbf{h})\end{array}$ \\
\hline T A & 0,68 & 0,72 & 0,88 & 81,81 & 0,30 \\
T B & 0,65 & 0,75 & 0,85 & 88,23 & 0,31 \\
T C & 0,65 & 0,70 & 0,85 & 82,35 & 0,29 \\
T D & 0,82 & 1,00 & 1,06 & 94,33 & 0,83 \\
T E & 1,39 & 1,78 & 1,81 & 98,34 & 1,48 \\
T F & 1,71 & 2,07 & 2,22 & 93,24 & 1,73 \\
\hline
\end{tabular}

* Média de cinco repetições 
Pode-se observar que os rendimentos GK foram altos para todos os tratamentos $(98,07 \%$ a $100,21 \%)$. Portanto, a eficiência com que o etanol foi convertido a ácido acético, para este cálculo de rendimento, é superior àquela calculada segundo AQUARONE $E$ ZANCANARO JR. [2].

A retirada de vinagre e reposição do mesmo volume de mosto alcoólico, quando a concentração de etanol baixava a níveis inferiores a $1,0 \%$ e a concentração de ácido acético alcançava teores de 5,0 a 8,0\% permitiu que o GK permanecesse aproximadamente constante, indicando que não houve perdas por evaporação ou superoxidação. A Figura 4 apresenta a produção média de ácido acético em função do tempo de fermentação, nos dois processos de acetificação.

TABELA 3. Produção de ácido acético e rendimento GK, durante a fermentação acética de vinhos de kiwi em seis tratamentos do experimento.

\begin{tabular}{cccccc}
\hline Tratamento & $\begin{array}{c}\text { Período de } \\
\text { acetificação } \\
\text { (h) }\end{array}$ & $\begin{array}{c}\text { Etanol \% } \\
(\mathbf{v} / \mathbf{v})^{*}\end{array}$ & $\begin{array}{c}\text { Ác. Acético } \\
\%(\mathbf{p} / \mathbf{v})^{*}\end{array}$ & GK & $\begin{array}{c}\text { Rendimento } \\
\text { GK (\%) }\end{array}$ \\
\hline T A & 0 & 2,05 & 5,23 & 7,28 & 98,07 \\
T B & 24 & 1,19 & 5,95 & 7,14 & \\
& 0 & 2,69 & 4,78 & 7,47 & 99,19 \\
T C & 24 & 1,88 & 5,53 & 7,41 & \\
& 0 & 3,09 & 4,61 & 7,70 & 98,44 \\
T D & 24 & 2,27 & 5,31 & 7,58 & \\
& 0 & 2,33 & 6,99 & 9,32 & 99,57 \\
T E & 12 & 1,29 & 7,99 & 9,28 & \\
& 0 & 2,90 & 6,55 & 9,45 & 100,21 \\
T F & 12 & 1,14 & 8,33 & 9,47 & \\
& 0 & 3,17 & 6,49 & 9,66 & 98,96 \\
& 12 & 1,00 & 8,56 & 9,56 & \\
\hline
\end{tabular}

* Média de cinco repetições

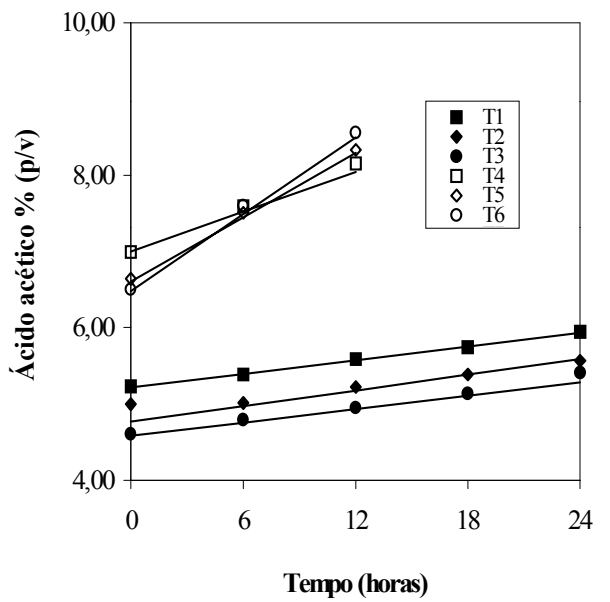

FIGURA 4. Produção média de ácido acético\% $(p / v)$ e duração (h) da fermentação acética de vinhos de kiwi nos processos gerador e submerso para diferentes tratamentos.

Observa-se que um vinagre com acidez acima de $8,0 \%(p / v)$ pode ser obtido em processo submerso com um tempo de 12 horas, nas condições desse experimento. Já para o processo do gerador, um tempo de 24 horas foi necessário para produzir vinagres com teores acima de $5,0 \%$ de ácido acético $(\mathrm{p} / \mathrm{v})$.

\subsection{1 - Análise estatística do componente etanol}

Verificou-se que o uso de diferentes concentrações de etanol não contribuiu para um aumento da produção de ácido acético para o processo do gerador. Por outro lado, no processo submerso, a diferença é significativa entre concentrações de etanol. Observou-se que para o tratamento 4 , o consumo de etanol foi menor quando comparado aos tratamentos E e F (Figura 3), os quais apresentaram um decaimento maior da concentração de etanol durante a fermentação acética, sendo assim, significativo em relação a estes. Comparandose apenas os tratamentos E e F, o efeito também é significativo. Por isso, a composição do mosto com teor de etanol mais alto, utilizada no processo submerso (TF), é a melhor, já que apresenta um coeficiente angular superior. A inclinação da reta é mais acentuada pelo maior consumo de etanol.

\subsection{2 - Análise estatística para a produção de ácido acético}

Para o processo do gerador a análise estatística revelou que o uso de diferentes concentrações de etanol não contribuiu para um aumento da produção de ácido acético. Os tratamentos com teor inicial de etanol de 2,13 e $2,44 \%$ (p/v) (TB e TC) não favoreceram um aumento na produção de ácido acético e, neste caso, TA $(1,62 \% \mathrm{p} / \mathrm{v})$ é economicamente melhor. Por outro lado, para o processo submerso, mais eficientes, tratamentos com teores de etanol superiores $(2,29$ e $2,5 \% \mathrm{p} / \mathrm{v}$ : TE e TF) produziram maior concentração de ácido acético. Pode-se dizer que o tratamento $\mathrm{F}$ (processo submerso), apresentou maior inclinação da reta, superando os demais tratamentos e, por isso, pode ser considerado superior em termos de produção de ácido acético.

\section{4 - Avaliação dos produtos finais}

\subsection{1 - Avaliação físico-química}

A Tabela 4 apresenta os resultados obtidos nas análises físico-químicas dos vinagres e os limites exigidos pela legislação vigente $[1,5,23]$. Como pode ser observado, os teores de ácido acético nos produtos finais ficaram aproximadamente em 5,0\% (p/v), e teores de etanol abaixo de 1,0\% (v/v). A análise microscópica dos vinagres de kiwi revelou ausência de sujidades, larvas e parasitas, o que indica que o processo foi higienicamente bem conduzido e que o produto encontra-se dentro dos padrões de qualidade para vinagre segundo a legislação vigente.

\subsection{2 - Avaliação sensorial}

$\mathrm{Na}$ avaliação sensorial, os valores calculados para os atributos cor e odor, não superaram o valor de $\chi^{2}$, correspondendo, respectivamente, a 8,702 e 7,453, 
portanto, não foram verificadas diferenças estatísticas entre os tratamentos analisados.

Quanto aos atributos aspecto, sabor e preferência geral, os dados analisados superaram o valor $\chi^{2}$ tabelado $(11,07)$, correspondendo a $98,03,94,12$ e 24,53 , respectivamente. Portanto, os tratamentos diferem entre si para estes atributos e, por isso, foi aplicado o teste de Tukey, para verificar onde ocorreram essas diferenças. Observou-se que existe diferença significativa entre os tratamentos $A$ e $D$; em relação ao aspecto. Os tratamentos B, C, E e F são estatisticamente iguais, sendo que os tratamentos 2 e 3 não apresentam diferença entre si.

TABELA 4. Características físico-químicas dos vinagres obtidos diluídos e limites estabelecidos pela Legislação.

\begin{tabular}{|c|c|c|c|c|c|c|c|}
\hline $\begin{array}{l}\text { Caracteristicas } \\
\text { físico-químicas }\end{array}$ & $T^{(T)}$ & $T^{\prime} B^{(1)}$ & $\mathrm{TC}^{(1)}$ & $T D^{(T)}$ & $T E^{(T)}$ & $T F^{(T)}$ & $\begin{array}{l}\text { Limites da } \\
\text { Legislação } \\
\text { Brasileira** }^{*}\end{array}$ \\
\hline Acidez \% (p/v) & 5,01 & 4,98 & 5,13 & 5,01 & 5,13 & 5,11 & 4,0 (mínimo) \\
\hline Etanol \% (v/v) & 0,54 & 0,70 & 0,65 & 0,49 & 0,32 & 0,41 & 1,0 (máximo) \\
\hline Res. Mineral fixo \% (p/v) & 0,18 & 0,15 & 0,16 & 0,11 & 0,17 & 0,13 & 0,1 (mínimo) \\
\hline Res. seco $105^{\circ} \mathrm{C} \%(\mathrm{p} / \mathrm{v})$ & 1,18 & 1,19 & 1,15 & 1,26 & 1,29 & 1,24 & 1,2 (mínimo) \\
\hline
\end{tabular}

* Média de três repetições

**Para vinagres de vinho e frutas. Fonte: São Paulo (1992).

As diferenças podem ser atribuídas, em parte, ao fato de que vinagres obtidos em processo submerso são turvos quando saem do fermentador, e mesmo com processos de filtração e clarificação, permanecem com qualidade inferior aos obtidos em processo por gerador, descaracterizando parte do brilho, pois, como podese observar na Tabela 5, os tratamentos obtidos em processo submerso apresentaram notas inferiores aos demais.

Para o atributo sabor, existem diferenças significativas entre as médias dos tratamentos $A$ e $D$. Os tratamentos B, C, E e F são estatisticamente iguais (Tabela 6).

TABELA 5. Análise estatística do atributo aspecto nos produtos finais obtidos na fermentação acética em seis tratamentos.

\begin{tabular}{cc}
\hline Tratamentos & Médias $\left(^{*}\right)$ \\
\hline T A & $2,89 \mathrm{a}$ \\
T C & $2,61 \mathrm{a} \mathrm{b}$ \\
T B & $2,56 \mathrm{ab}$ \\
TF & $2,06 \mathrm{ab}$ \\
TE & $2,00 \mathrm{ab}$ \\
T D & $1,67 \quad \mathrm{~b}$ \\
\hline
\end{tabular}

(*) Médias assinaladas com a mesma letra, não diferem entre si, pelo teste de Tukey ao nível de $5 \%$ de significância.

O vinagre obtido pelo TA foi um pouco superior quanto ao sabor e segundo os julgadores, apresenta um aroma agradável e o sabor ácido próprio da fruta. Alguns julgadores verificaram um sabor adstringente e muito picante, nos vinagres dos tratamentos D, E e F. Aplicando-se o teste de Tukey para verificar a preferência geral dos julgadores pelo índice de aceitabilidade, foi observado que houve variação significativa entre os tratamentos. O tratamento A foi superior e o tratamento $D$ inferior, o mesmo tendo sido observado para o atributo sabor. Os tratamentos B, C, E e F são estatisticamente iguais ao nível de significância de $5 \%$. Por outro lado, TA é diferente de TD e TE, e também diferem entre si os tratamentos B e D (Tabela 7).

TABELA 6. Análise estatística do atributo sabor nos produtos finais obtidos na fermentação acética em seis tratamentos.

\begin{tabular}{cc}
\hline Tratamentos & Médias $\left(^{*}\right)$ \\
\hline T A & $2,94 \mathrm{a}$ \\
T B & $2,53 \mathrm{a} \mathrm{b}$ \\
T C & $2,33 \mathrm{a} \mathrm{b}$ \\
T F & $2,16 \mathrm{a} \mathrm{b}$ \\
T E & $2,11 \mathrm{a} \mathrm{b}$ \\
T D & $1,64 \mathrm{~b}$ \\
\hline
\end{tabular}

(*) Médias assinaladas com a mesma letra, não diferem estatisticamente, pelo teste de Tukey ao nível de $5 \%$ de significância.

Considerando-se TA com índice de aceitabilidade de $100 \%$, observou-se que os tratamentos $E$ e D não atingiram o valor mínimo de $70 \%$ para serem aceitos pelo consumidor [29]. Os índices de aceitabilidade para os tratamentos A, B, C e F são semelhantes aos encontrados por ILHA et al [12] e PETERSON et al [22] na análise sensorial de vinagre de mel que variou entre 95,37 e $75,56 \%$. Segundo alguns julgadores, os vinagres obtidos em processo submerso apresentaram odor desagradável acentuado. Segundo MANFROI et al [16], isso pode ocorrer devido a presença de células microbianas que ficam no meio em suspensão durante a fermentação submersa e que podem permanecer no produto mesmo após os tratamentos finais. Além disso, em vinagres recém elaborados, o ácido acético supera os demais componentes do aroma, os quais vão se tornando mais intensos ao longo do tempo.

TABELA 7. Análise estatística da preferência geral e índice de aceitabilidade dos produtos finais obtidos na fermentação acética em seis tratamentos.

\begin{tabular}{ccc}
\hline Tratamentos & Médias $\left(^{*}\right)$ & Índice de aceitabilidade (\%) \\
\hline T A & $2,89 \mathrm{a}$ & 100,00 \\
T B & $2,33 \mathrm{a} \mathrm{b}$ & 80,62 \\
T C & $2,22 \mathrm{a} \mathrm{b} \mathrm{c}$ & 76,82 \\
T F & $2,11 \mathrm{a} \mathrm{b} \mathrm{c}$ & 73,01 \\
T E & $1,33 \mathrm{~b} \mathrm{c}$ & 46,02 \\
T D & $1,11 \quad \mathrm{c}$ & 38,41
\end{tabular}

$\left(^{*}\right)$ Médias assinaladas com a mesma letra, não diferem estatisticamente entre si, pelo teste de Tukey ao nível de $5 \%$ de significância.

\section{4 - CONCLUSÕES}

- Foi possível produzir vinhos de kiwi utilizando uma cultura pura de S. cerevisiae como inóculo, e a utilização de bactérias acéticas provenientes de vinagre de mel foi eficiente na conversão de etanol em ácido acético. 
- A adição de nutrientes aos mostos não influenciou a produção de etanol, já que a fruta contém fatores de crescimento necessários ao desenvolvimento dos microrganismos. Por outro lado, a adição de sacarose comercial aumentou a produção de etanol.

- O tratamento com menor concentração de etanol inicial $(1,62 \% \mathrm{p} / \mathrm{v})$, a princípio, foi considerado mais econômico para o processo do gerador, visto que não foi, necessária a adição de açúcares para a correção do mosto para a fermentação alcoólica. Ao contrário, no processo submerso, maiores concentrações de vinho no mosto $(2,50 \% \mathrm{p} / \mathrm{v})$, foram mais produtivas e por isso podem ser consideradas mais eficientes na produção de vinagre de kiwi.

- A velocidade de acetificação foi superior no processo submerso, com maiores rendimentos e produtividades.

- No contexto da pequena propriedade, o processo do gerador se apresenta mais adequado pela qualidade do produto final. Por outro lado para pequenas e médias indústrias, o processo submerso é favorável, em função de maior rendimento e produtividade.

- A análise através do teste de ordenação indicou que os vinagres, especialmente os obtidos pelo processo do gerador, poderiam ser aceitos pelo consumidor.

\section{5 - REFERÊNCIAS BIBLIOGRÁFICAS}

[1] ABNT - Associação Brasileira de Normas Técnicas. NBR 13170 - Teste de Ordenação em Análise Sensorial. 1994. 7 p.

[2] AQUARONE, E.; ZACANARO JÚNIOR, O. Vinagres. In: AQUARONE, E., LIMA, U. A., BORZANI, W. (coords): Alimentos e bebidas produzidos por fermentação Biotecnologia. São Paulo: E. Blücher, v. 5, 1983. p. 104$122,243 p$.

[3] AOAC - ASSOCIATION OF OFFICIAL ANALYTICAL CHEMISTRY. Official Methods of Analysis of the Association of Analytical Chemists. 15. ed. Arlington: Sidney William , 1999. $1268 p$.

[4] BHATT, S.; RANA, R.S. AND NAIN, L.R. Ethanol production from mixed fruit juice of damage guava and banana. Journal of Food Science and Technology, v. 24, 1997. p. 192-193.

[5] BRASIL. Resolução n. 12, de 30 de março de 1978. Aprova as seguintes normas técnicas especiais do Estado de São Paulo, revistas pela C.N.N.P.A. relativas a alimentos e bebidas, para efeito em todo o território brasileiro. Diário Oficial da União: Brasília, 24 de julho de 1978, Seção 1 pt1.

[6] CIANI, M. Wine vinegar production using base wines made with different yeast species. Journal of the Science of Food and Agricultural. n.2, v.78, 1998. p.290-294.

[7] EBNER, H. Vinegar. IN: Reed, G. (ed.) Industrial Microbiology. Westport : AVI, 1982. 883p. p. 802-834.

[8] EMBRAPA. Informática agropecuária. Base de Dados da Pesquisa Agropecuária. Disponível na Internet. http:// uww.cnptia.embrapa.br/cgi_bin/util, 10 de dezembro de 1999.

[9] EPAGRI - EMPRESA DE PESQUISA AGROPECUÁRIA E EXTENSÃO RURAL DE SANTA CATARINA. Relatório Anual de Fruticultura de Clima Temperado. EPAGRI. Videira, 2000.
[10] EVANGELISTA, J. Tecnologia de Alimentos 2 ed. Rio de Janeiro: Atheneu, 1989. 652 p.

[11] FUKAYA, M.; PARK, T. S.; TODA, K. Improvement of acetic acid fermentation by molecular breeding and process development. Journal of Applied Bacteriology, v. 73, n. 6, 1992. p. 447-454.

[12] ILHA, E. C.; SANT'ANNA, E. S.; TÔRRES, R.C. DE O. et al. Utilization of bee (Apis melifera) honey for vinegar production. Boletim CEPPA-Centro de Pesquisa e Processamento de Alimentos. Curitiba v.18 n.1, 2000. p. 39-50.

[13] INSTITUTO ADOLFO LUTZ. Normas analíticas: métodos químicos e físicos para análise de alimentos. 3. ed. São Paulo, 1985. 583 p. p. 281-283.

[14] JACKMAN, E. A. Alcohol industrial. In: BU'LOCK, J., KRISTIANSEN, B. Biotecnologia Básica. Zaragoza: Acribia, 1991. 557 p. p. 320-321.

[15] LU, S.F.; LEE, F-L.; CHEN, H.K. A thermotolerant and high acetic acid- producing bacterium Acetobacter sp 114-2. Journal of Applied Microbiology, v. 86, n.1, 1999. p. 55-62.

[16] MANFROI, V.; MIOLO, A.; PERIN, J. Fermentado de quivi. Revista Brasileira de Fruticultura. Cruz das Almas. v. 18, 1996. p. 151-154.

[17] MECCA, F.; ANDREOTTI, R.; VERONELLI, L. L'aceto: tecnologia industriale e tradizionale emprego nell industria conserveira utilizzazione in cucina. Brescia, 1. Ed., 1979. 320 p.

[18] MISLIVEC, P. B.; STACK, M. E.; KOCH, H. A. et al. Yeasts, molds and mycotoxins. In: Food and Drug Administration. Bacteriological Analytical Manual. 7 ed. Arlington : AOAC International, 1992. 529 p. p. 228-229.

[19] MONTEIRO, C. L. B. Análise sensorial : seleção e treinamento de equipes de degustadores. Boletim CEPPA, Curitiba, v. 2, n. 1. jan./jul. 1984.

[20] NOVOA, M. A. O.; PALACIOS, C. A. M.; LEÓN, E. R. M. Manual de técnicas para laboratório de nutrición de peces y crustaceos. México : ONU, 1993. 104p. p. 3335. (Doc. de Campo, 7.)

[21] NUCCI, T.A. Cultura do kiwi. Instituto Agronômico de Campinas. Jaboticabal: FUNEP, 1996. 28 p.

[22] PATERSON, V.J.; MACRAE, E.A.; YOUNG, H. Relationships between sensory properties and chemical composition of kiwifruit (Actinidia deliciosa) Journal of the Food of Science and Agricultural. v. 51, n. 2, 1991. p. 235-251.

[23] SÃO PAULO. Sec. de Est. Saúde. Código Sanitário. 5. ed. SãoPaulo: 1992. 412p. p. 306-307. v. 1, p. 150-152.

[24] SAS INSTITUTE INC. Sas Campus Drive. Cary, NC, USA. Sas Isntitute Inc. Sas Systen for Windows, versão 6.12, 1996.

[25] SHIROSE, I.; MORI, E. E. M. Estatística aplicada à análise sensorial. Campinas : ITAL, 1994. v. 1, 73p. (Manual Técnico do Instituto de Tecnologia de Alimentos).

[26] SOKOLLEK, S.J.; HERTEL, C.; HAMMES, W.P. Description of Acetobacter oboediens sp nov. and Acetobacter pomorum sp. Nov., two new species isolated from industrial vinegar fermentations. International Journal of Systematic Bacteriology n. 48, 1998. p. 935-940.

[27] STATISTICAL GRAPHICS SYSTEM, Inc. and Statistical Graphics Corporation, versão 7,0 - STSC 1985.

[28] TAKAOMI, I.; HIROYUKI, S.; HIROYUKI, H et al. Eficient acetic acid production by repeated fed-batch fermentation using two fermentors. Applied Microbiology and Biotechnology v. 36, n. 3, 1991. p. 295-299.

[29] TEIXEIRA, E.; MEINERT, E. M.; BARBETTA, P.A. Análise sensorial de alimentos. Florianópolis : UFSC, 1987.180 p. 